\title{
On Dynamics of the Biggest Lift Bridge in the World ROSKO Peter ${ }^{1, a}$ \\ ${ }^{1}$ Vienna university of Technology \\ Center of Mechanics and Structural Dynamics \\ Karlsplatz 13/E2063 \\ A-1040 Vienna \\ Austria, Europe \\ apeter.rosko@tuwien.ac.at
}

Keywords: Lifting bridge, dynamics.

Abstract. The paper deals with dynamic analysis of biggest lift bridge in the world. The Botlek bridge is placed in Rotterdam area and currently is under construction. The bridge is unique and the design required concurrent know-how from mechanics theory and technology practice. The statically and dynamically loaded finite element model of the bridge was investigated on the base of Eurocode. The paper focuses on the basic ideas of the design and analyses. Selected results illustrate the presented bridge project.

\section{Introduction}

The project of the new Botlek bridge was initiated in framework of transport infrastructure improvement in Rotterdam, Holland. The comprehensive analysis of the unique project led to the optimized final design. The design required concurrent know-how from mechanics theory and technology practice. The Botlek bridge is currently is under construction and will be the biggest vertical-lift bridge in the world. The paper focuses on the basic ideas of the design and analyses in dynamics.

\section{Structure}

The vertical-lift bridge with two spans bear six freeway lanes, two railroads and a foot path for pedestrians. The length of each steel deck is $94 \mathrm{~m}$ and the width is $49 \mathrm{~m}$. The height of six reinforced concrete pylons is more than $50 \mathrm{~m}$ afloat. Dimension ratios of the designed bridge visually correspond to ratios of common smaller bridges (see Fig. 1 and Fig .2).

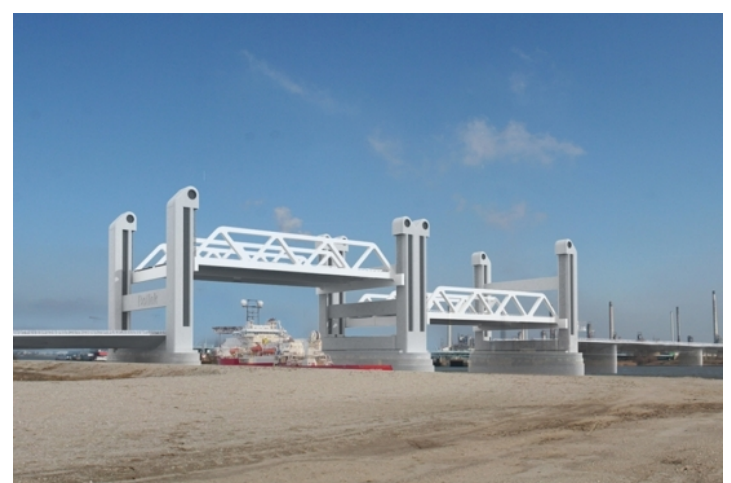

Fig. 1 Botlek bridge - visualization



Fig. 2 Botlek bridge - plan

Each end cross beam of deck is connected with cables to the concrete counterweight. Both decks and four counterweights are guided in pylons. The weight of counterweights is approximately in equilibrium with weight of the decks. 


\section{Finite element model}

The finite element model was designed and analyzed in ANSYS environment. Models of the deck and pylons are shown in Fig. 3-6.

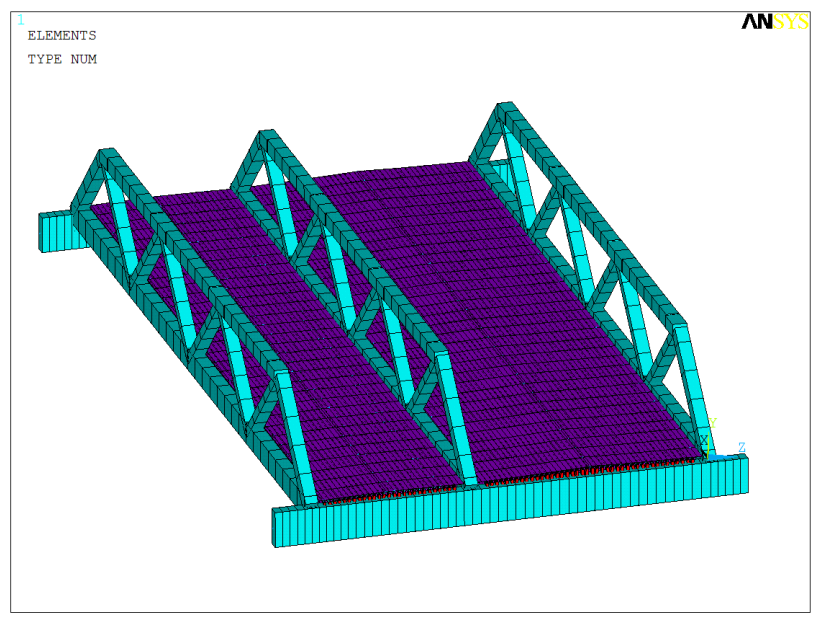

Fig. 3 Finite element model of the deck, view: top



Fig. 4 Detail of deck model, view: bottom

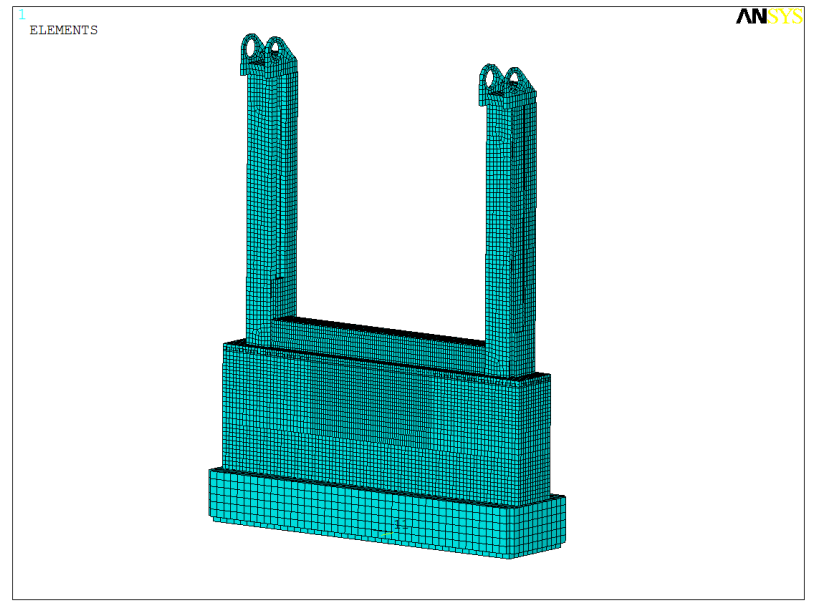

Fig. 5 Finite element model of the end pylons: pier 30 and pier 50

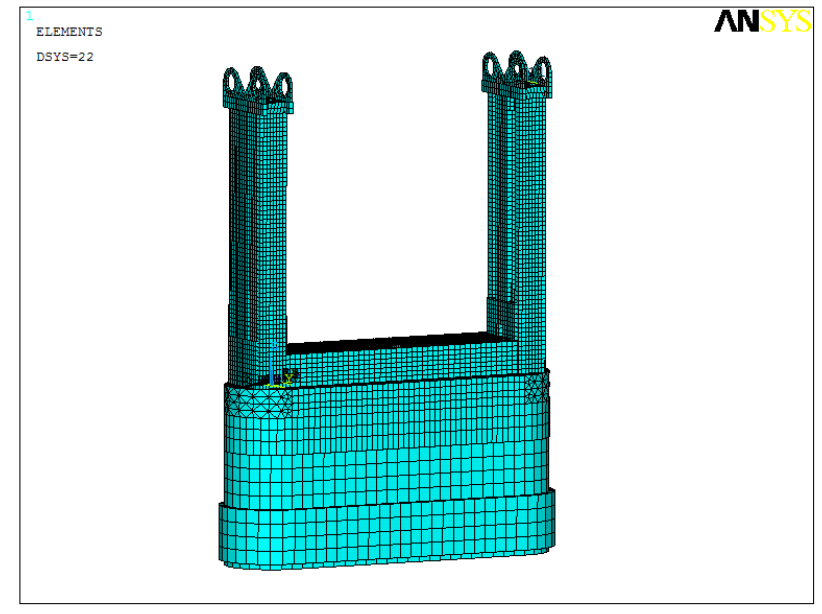

Fig. 6 Finite element model of the central pylons: pier 40

\section{Analysis in dynamics}

The modal analysis provided the clear view on the stiffness and mass distribution and offered the idea about dynamic behavior of the structure. In the preliminary design of the structural elements of the lifting bridge were analyzed separately (see Fig.7-9) and in the next step the whole system was analyzed using the component mode synthesis (see scheme in Fig.10) [1]. The dynamically loaded finite element model of the bridge was investigated on the base of Eurocode. The response spectrum analyses were applied for dynamics of wind loading, earthquake loads, road and railway loads. Decoupling of the lifting bridge system in operating position enabled to analyze the deck and the pylons separately. The complete system with various positions of decks and counterweights were considered for wind and earthquake loads. The movement of decks and counterweights and ship impact were analyzed separately. Selected results illustrate the presented bridge project (Fig. 7-10). 




Fig. 7 First three modes of the deck, view from the top and view from the bottom 

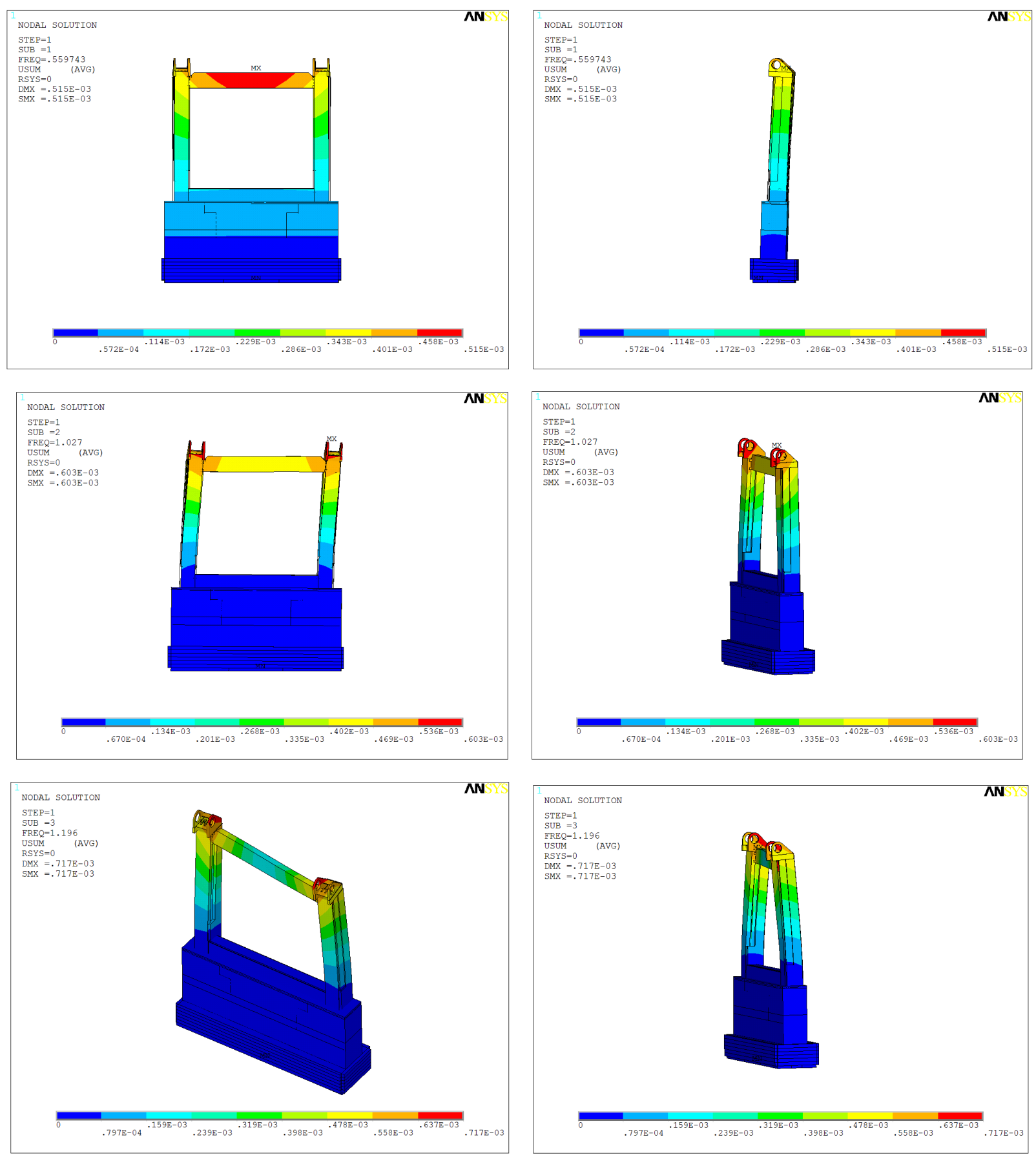

Fig. 8 First three modes of the side pylons with counterweight, side views 

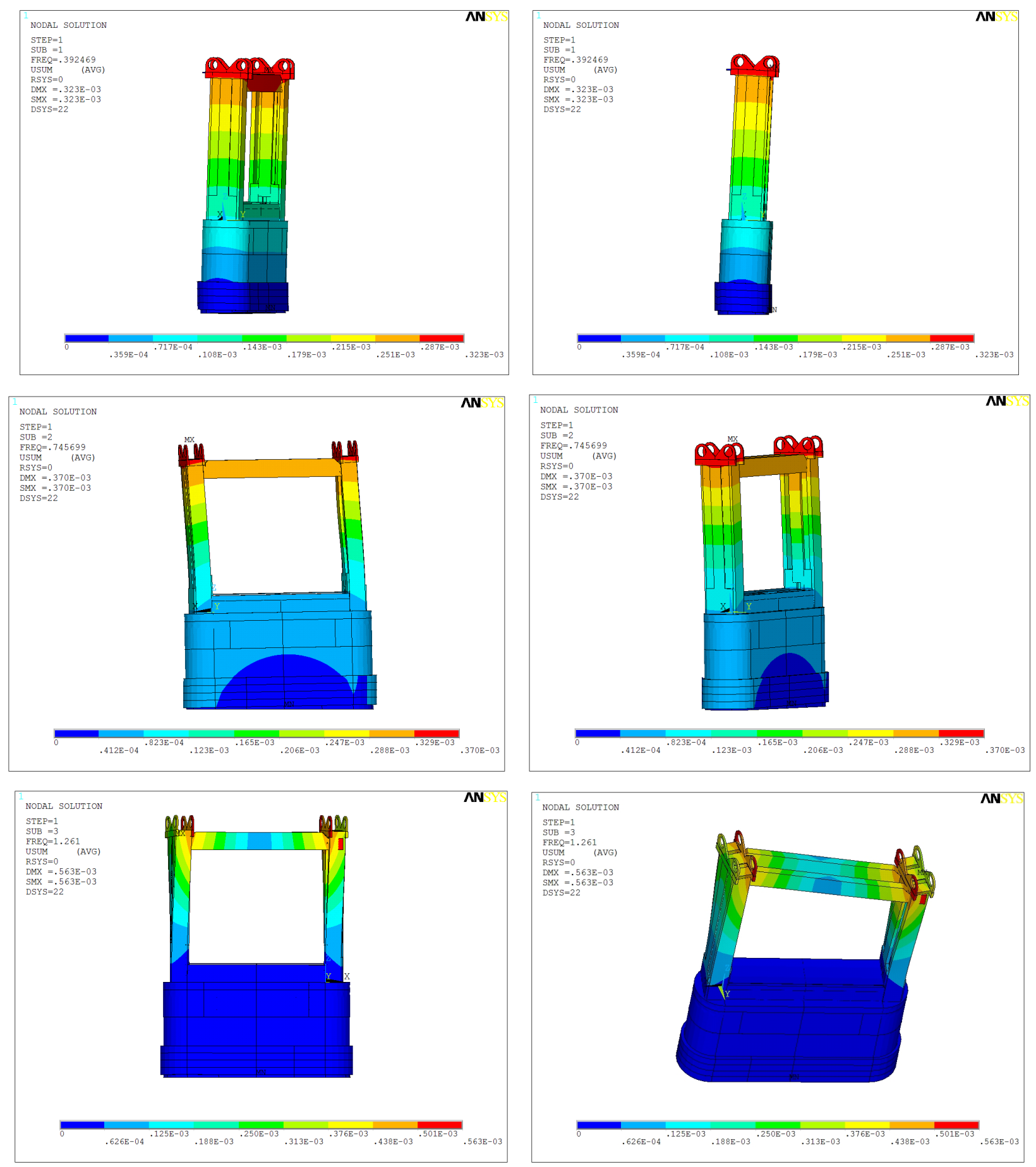

Fig. 9 First three modes of the middle pylons with counterweight, side views 




Fig. 10 Scheme of complete system in plan view: two decks, pylons and counterweights.

\section{Summary}

Results of the vertical-lift bridge modal analyses on the structural element level and on the whole system level are useful for response spectrum analyses. The component mode synthesis enables to analyze the lifting bridge in various positions of decks. The analyses and design meet requirements of Eurocode.

\section{References}

[1] P. Rosko: Models of structures in statics and dynamics (PR, Bratislava 2015) in press. 